\title{
Neuroendoscopy : Current and Future Perspectives
}

\author{
Kyu Won Shim, M.D., Ph.D., ${ }^{1}$ Eun Kyung Park, M.D., 'Dong-Seok Kim, M.D., Ph.D., ${ }^{1 *}$ Joong-Uhn Choi, M.D., Ph.D. ${ }^{2 *}$ \\ Department of Pediatric Neurosurgery, ${ }^{\prime}$ Severance Children's Hospital, Yonsei University College of Medicine, Brain Korea 21 Project for \\ Medical Science, Seoul, Korea \\ Department of Neurosurgery, ${ }^{2}$ Chaum Hospital, Cha University, Seoul, Korea
}

Neuroendoscopic surgery is performed because it causes minimal damage to normal structures, carries a lower rate of complications, and achieves excellent outcomes. Surgeons using an endoscope and related instruments can perform complex operations through very small incisions, which is especially useful for minimally invasive procedures for the brain and spine. Neuroendoscopic surgery is now performed in cases of obstructive hydrocephalus, various intraventricular lesions, hypothalamic hamartomas, craniosynostosis, skull base tumors, and spinal lesions. This review discusses the brief history of neuroendoscopy and the current state and future perspectives of endoscopic surgery.

Key Words : Neuroendoscopy · Ventriculostomy · History · Endoscope.

\section{BRIEF HISTORY}

In 1910, L'Espinasse performed the first neurosurgical endoscopic procedure for choroid plexus fulguration in two infants with hydrocephalus. Using a cystoscope, one infant was successfully treated ${ }^{16,21,23)}$. Walter Dandy used an endoscope to perform an unsuccessful choroid plexectomy in $1922^{91}$. The next year, Mixter ${ }^{17)}$ used a urethroscope to complete the first successful endoscopic third ventriculostomy (ETV) in a 9-month-old girl with obstructive hydrocephalus. In 1935, Scarff reported his initial results after using a novel endoscope equipped with a cauterizing electrode, an irrigation system to prevent ventricle collapse, and a movable operating tip to perforate the third ventricle floor ${ }^{16,23)}$.

In 1952, Nulsen and Spitz ${ }^{18}$ began the era of ventricular cerebrospinal fluid (CSF) shunting, marking the end of the initial era of neuroendoscopy. The period of darkness in neuroendoscopy continued until 1970s, but interest in ETV for treating obstructive hydrocephalus was renewed with the improved imaging capability of endoscopes. In 1978, Vries $^{22)}$ described his experience treating five patients with hydrocephalus, in whom he demonstrated that ETVs were technically

- Received : February 10, 2017 -Revised : March 30, 2017 -Accepted : April 6, 2017

- Address for reprints : Joong-Uhn Choi, M.D, Ph.D.

Department of Neurosurgery, Chaum Hospital, Cha University, 442 Dosan-daero, Gangnam-gu, Seoul 06062, Korea

Tel : +82-2-3015-5030, Fax : +82-2-3015-5315, E-mail : juchoi@yuhs.ac

Dong-Seok Kim, M.D., Ph.D.

Department of Pediatric Neurosurgery, Severance Children's Hospital, Yonsei University College of Medicine, 50-1 Yonsei-ro, Seodaemun-gu, Seoul 03722, Korea Tel : +82-2-2228-2150, Fax : +82-2-393-9979, E-mail : dskim33@yuhs.ac

* These authors are co-corresponding authors.

This is an Open Access article distributed under the terms of the Creative Commons Attribution Non-Commercial License (http://creativecommons.org/licenses/by-nc/4.0) which permits unrestricted non-commercial use, distribution, and reproduction in any medium, provided the original work is properly cited. 
feasible using a fiberoptic endoscope. In 1990, Jones and colleagues ${ }^{15)}$ described a $50 \%$ shunt-free success rate for ETV in 24 patients with various forms of hydrocephalus. Four years later, the same group reported an improved success rate of $61 \%$ in a series of 103 patients $^{14)}$. Currently, ETV is primarily used to treat obstructive hydrocephalus due to benign aqueductal stenosis or compressive periaqueductal mass lesions. Modern shunt-free success rates range from 80 to $95 \%{ }^{16,21)}$.

\section{CURRENT STATUS OF NEUROENDOSCOPY}

The field of neuroendoscopy has extended beyond ventricular procedures. The endoscope is currently used for all types of neurosurgically treatable diseases such as intracranial cysts, intraventricular tumors, hypothalamic hamartoma $(\mathrm{HH})$, skull base tumors, craniosynostosis, degenerative spine disease, and rare subtypes of hydrocephalus.

\section{Treatment of hydrocephalus}

ETV is a popular standard treatment for obstructive hydrocephalus. It is the first-line approach in cases of aqueductal stenosis, with a success rate above $60 \%$. ETV is equally effective in treating hydrocephalus due to tectal plate lesions ${ }^{8,24)}$. The results of ETV in patients are influenced by hydrocephalus etiology and patient age. Congenital hydrocephalus and that combined with myelomeningocele are not satisfactorily treated in very young children, but success rates are better in older children and adolescents $(>70 \%)^{8,16)}$.

In patients with midline posterior fossa tumors, preoperative ETV is considered in severe hydrocephalus requiring urgent management. ETV is also suitable for postoperative hydrocephalus as an alternative to shunt insertion ${ }^{16,21}$.

Use of the endoscope has also been explored for other complicated forms of hydrocephalus. Septostomy or septum pellucidotomy can be performed endoscopically to treat isolated lateral ventricles. Fenestration of loculated ventricles due to various causes can also be performed by endoscopy. Aqueductoplasty was recently reported for the treatment of trapped fourth ventricle syndrome. Applied neuroendoscopic techniques have been extended to foraminoplasty of the foramens of Monro and Magendie, as well as endoscopic fourth ventriculostomy ${ }^{16,19,21)}$.

\section{Treatment of cysts and intraventricular tumors}

Endoscopic procedures include cyst fenestration, tumor biopsy, tumor removal, and metastatic disease assessment. Suprasellar or quadrigeminal arachnoid cysts presenting with hydrocephalus are good candidates for endoscopic fenestration. Most patients with intraventricular cyst or tumors have concomitant hydrocephalus. This makes endoscopic surgery particularly advantageous, as simultaneous procedures can be performed for both CSF diversion and tumor management ${ }^{6,7)}$. Endoscopic tumor biopsy is a well-established method for intraventricular brain tumors. It has a high diagnostic yield $(>90 \%)$ and low risk (<3.5\%). Germ cell tumor, infiltrative hypothalamic/optic pathway glioma, and Langerhans cell histiocytosis are addressable with endoscopic biopsy ${ }^{21)}$. Endoscopic removal is suitable for colloid cysts or tumors that are also pedunculated at the ependymal surface. Endoscopic excision of a colloid cyst is technically feasible through the lateral ventricle in most cases unless the cyst is very large, which increases the risk of venous injury at the foramen of Monro ${ }^{21,25)}$. Transventricular endoscopic tumor cyst decompression can temporarily or permanently alleviate obstructive hydrocephalus or visual loss. It can be employed in patients with craniopharyngioma, hypothalamic/chiasmatic astrocytoma, and suprasellar or pineal germ cell tumors. Total removal of the solid tumor is limited due to the inadequacy of compatible endoscopic instrumentation and limited bleeding control. The success of endoscopic tumor removal depends on tumor size, density, and vascularity ${ }^{21,25)}$. Extraventricular arachnoid cyst located at the sylvian fissure or interhemispheric fissure and posterior fossa can be treated with endoscopic approaches. Endoscopic fenestration can be safely performed from inside of the cyst into the surrounding subarachnoid space ${ }^{6}$.

\section{Treatment of $\mathrm{HH}$}

HHs are rare non-neoplastic congenital malformations arising from the inferior hypothalamus and associated with gelastic seizures, precocious puberty, and cognitive problems. All patients except those with precocious puberty require surgical treatment. Single or combination treatment should be used according to HH type (classified by Delalande and Fohlen ${ }^{5}$ or Choi et $\left.\mathrm{al}^{2,3}\right)$. The transcallosal craniotomy approach is preferred for large HHs. Gamma knife surgery is an option for small lesions. Stereotactic radiofrequency thermocoagulation 
has been safely applied for small- or medium-sized HHs with good short-term results. Endoscopic resection assisted with stereotactic navigation has been attempted to surgically remove small HHs, but parts of the tumors remained. Surgeries to resect $\mathrm{HHs}$ are typically performed in multiple steps. Nevertheless, recent reports indicate that endoscopic disconnection of HHs seems to be safer and more effective than other modalities ${ }^{3,20)}$. In most cases, navigation assistance is recommended because lateral and third ventricles are normal sizes in these patients.

\section{Treatment for skull base lesions}

Neuroendoscopy for skull base tumors began with Carrau and colleagues ${ }^{1)}$, who reported their original experience of endonasal transsphenoidal hypophysectomy at the University of Pittsburgh. de Divitiis and colleagues ${ }^{4)}$ expanded the scope of this approach to include other lesions of the sellar and parasellar regions. The bilateral endonasal endoscopic approach now allows for visualization of tumors at the anterior skull base up to the crista galli and down to the level of $\mathrm{C} 2$. The endoscopic endonasal technique has been applied for surgical excision of pituitary adenoma and craniopharyngioma with encouraging results and low morbidity. The route of the endoscopic approach for sellar or suprasellar tumors should be based on the extent of lesion. Supradiaphragmatic lesions can be removed via the endonasal route, and suprasellar prechiasmatic preinfundibular lesions can be removed with the transtuberculumtransplanum sphenoidale approach ${ }^{211}$.

Endoscopic treatment has been applied for the treatment of CSF rhinorrhea, which commonly occurs as the result of trauma and iatrogenic disruption of the skull base and secondary to inflammatory, neoplastic, and pseudotumor syndromes. Skull base defects can be repaired with endoscopic remodeling of tissue planes and complete separation of the cranial space and sinonasal cavities to perform a multilayered reconstruction. Small bony defects can be closed with a single layer of autologous fat or fascia, followed by tissue sealant. Larger skull base defects with a high-volume intraoperative CSF leaks require multilayered closure. This can be achieved with an autologous fat graft in the bony defect followed by fascia lata, bony buttress, and tissue sealant. These larger skull base defects can be supplemented with a gasket seal closure ${ }^{21}$.

\section{Surgery for craniosynostosis}

Jimenez and colleagues ${ }^{12,13)}$ pioneered minimally invasive surgical treatment of craniosynostosis. This condition can be corrected with endoscopy-assisted craniosynostosis surgery (EACS) before the age of 6 months combined with postoperative helmet molding therapy. The optimal age for EACS is 3 months. The procedure is essentially strip craniectomy and can be performed with a standard armamentarium and a $0^{\circ}$ endoscope with a working shaft used for endoscopic facial lift surgery without irrigation. The authors reported a low complication rate and good success rate. A separate aspirator parallel to the endoscope is used for blood aspiration.

In scaphocephaly, the craniectomy is performed from the anterior to the posterior fontanelle. The bone is cut with strong scissors. The removed strip should be $4-5 \mathrm{~cm}$ wide and $11 \mathrm{~cm}$ long. Lateral barrel stave osteotomies or wedge-shaped osteotomies can be added behind the coronal suture and in front of the lambdoid sutures. This endoscopic approach has a low reported complication rate and good success rate. Furthermore, only $9 \%$ of 139 patients required blood transfusion in their most recent publication. The children wear a helmet within 3 weeks postoperatively for 10 months. Special attention is paid for possible pressure ulcerations or eczema, but skin complications are $\operatorname{rare}^{12,13,21)}$.

\section{Spinal endoscopic surgery}

In the last decade, the neuroendoscope has been increasingly used in the surgical management of both intra- and extradural spinal diseases. Fenestration of intradural arachnoid cysts can be easily performed with the endoscope. In the 1990s, it was popular to dissect the septations of multiloculated syringomyelia cavities, but their clinical and radiological benefits were limited ${ }^{11)}$.

The neuroendoscope is an important part of the minimally invasive spine surgery movement. Endoscopic approaches have expanded to thoracoscopic sympathectomy, discectomies, lumbar laminotomies, anterior approaches for spinal reconstruction, and resection of tumors and cysts. Endoscopic discectomy is increasingly performed in both the thoracic and lumbar regions. Epiduroscopy is used in patients who have peridural fibrosis following spinal procedures, but its success and usefulness must be followed up further ${ }^{10,21}$. 


\section{Neuroendoscopic treatment of intraparenchymal lesions}

Improved illumination and vision of endoscopes has led to the possibility of working in the brain parenchyma. The concept of a keyhole craniotomy combined with a selected trajectory enables the endoscopic approach of intraparenchymal lesions with an assisted navigation system. Endoscopic resection is then performed by introducing instruments through the sheath, and various instruments such as suction tubes, tumor forceps, microscissors, and monopolar or bipolar coagulation can be used for lesion resection. To ensure efficient operation under a good endoscopic view, it is very important to maintain good intraoperative irrigation and drainage $e^{21)}$.

Partial or total lesion removal may be achieved depending on the nature of tumor. Selected cases for this endoscopic surgery remain limited but include cavernous angiomas, intraparenchymal hematomas, cerebellar infarctions, and brain abscesses. This technique was demonstrated to be accurate and safe and possibly will be expanded to remove other intraparenchymal lesions in the future ${ }^{21)}$.

\section{Neuroendoscopy-assisted microsurgery}

Many neurosurgeons have recently used the neuroendoscope to assist with "traditional" skull base microsurgery. The endoscope has already been reported as a useful adjunct to the microscope in anterior skull base surgeries, posterior fossa approaches, and aneurysm surgery. The microscopic approach makes dissected structures visible in a straight line with the great advantages of high resolution, excellent color fidelity, and stereoscopic vision. For working "around a corner," the endoscope is applied to reduce retraction and skull base drilling.

In endoscope-assisted microsurgery, most of the procedure is performed under a microscopic view because of the better image quality. However, endoscopic approaches are used in certain steps. The endoscope is mostly used to look around bony or dural corners, as well as neurovascular structures, to avoid retraction and extensive skull base drilling. Frequently, the endoscope is simply used freehand for inspection. However, when bimanual dissection is required, the endoscope is fixed to a self-retaining holding device, and the surgeon has both hands free for manipulation ${ }^{1,4,21}$.

The endoscope-assisted technique has proven useful in skull base surgery for tumors (pituitary tumor, craniopharyngioma, acoustic neuroma, epidermoid), aneurysm clipping, and trigeminal microvascular decompression ${ }^{21)}$.

\section{FUTURE PERSPECTIVES}

The future of neuroendoscopic surgery is likely to be bright. The field will benefit from further miniaturization of cameras and optical technology, innovations in surgical instrumentation design, the introduction of new navigation or robotics systems, new technological advances such as multiport endoscopic surgery, and an enhanced ability to perform endoscope-assisted microsurgery with bimanual microdissection. With ongoing development of endoscopic instruments and advanced surgical techniques including multiport approaches, endoscopic surgery will be expanded beyond intraventricular and skull base lesions to intraparenchymal brain lesions. These advances will be important for the future of endoscopeassisted microsurgery.

Other goals are telemanipulated neurosurgery with supervisory-controlled robotic systems, shared control systems, and even fully robotic telesurgery. Nanotechnology developments are needed to address future indications for minimally or even ultramicro-access neurosurgery.

In the future, neuroendoscopy is expected to become routine in modern neurosurgical practice. Institutions should develop training programs for young neurosurgeons.

\section{References}

1. Carrau RL, Jho HD, Ko Y : Transnasal-transsphenoidal endoscopic surgery of the pituitary gland. Laryngoscope 106 : 914-918, 1996

2. Choi JU, Kim DS : Treatment modalities for intractable epilepsy in hypothalamic hamartoma. Adv Tech Stand Neurosurg 39 : 117-130, 2012

3. Choi JU, Yang KH, Kim TG, Chang JH, Chang JW, Lee BI, et al. : Endoscopic disconnection for hypothalamic hamartoma with intractable seizure. Report of four cases. J Neurosurg 100(5 Suppl Pediatrics) : 506-511, 2004

4. de Divitiis E, Cappabianca P, Cavallo LM : Endoscopic transsphenoidal approach: adaptability of the procedure to different sellar lesions. Neurosurgery 51 : 699-705; discussion 705-707, 2002

5. Delalande 0 , Fohlen $\mathrm{M}$ : Disconnecting surgical treatment of hypothalamic hamartoma in children and adults with refractory epilepsy and proposal of a new classification. Neurol Med Chir (Tokyo) 43 : 61- 
68, 2003

6. Di Rocco F, Yoshino M, Oi S : Neuroendoscopic transventricular ventriculocystostomy in treatment for intracranial cysts. J Neurosurg 103(1 Suppl) : 54-60, 2005

7. Fukushima T, Ishijima B, Hirakawa K, Nakamura N, Sano K : Ventriculofiberscope: a new technique for endoscopic diagnosis and operation. Technical note. J Neurosurg 38 : 251-256, 1973

8. Hopf NJ, Grunert P, Fries G, Resch KD, Perneczky A : Endoscopic third ventriculostomy: outcome analysis of 100 consecutive procedures. Neurosurgery 44 : 795-804; discussion 804-806, 1999

9. Hsu W, Li KW, Bookland M, Jallo Gl : Keyhole to the brain: Walter Dandy and neuroendoscopy. J Neurosurg Pediatr 3 : 439-442, 2009

10. Ikuta K, Arima J, Tanaka T, Oga M, Nakano S, Sasaki K, et al. : Shortterm results of microendoscopic posterior decompression for lumbar spinal stenosis. Technical note. J Neurosurg Spine 2 : 624-633, 2005

11. Ishii K, Matsumoto M, Watanabe K, Nakamura M, Chiba K, Toyama Y : Endoscopic resection of cystic lesions in the lumbar spinal canal: a report of two cases. Minim Invasive Neurosurg 48 : 240-243, 2005

12. Jimenez DF, Barone CM : Endoscopic craniectomy for early surgical correction of sagittal craniosynostosis. J Neurosurg 88 : 77-81, 1998

13. Jimenez DF, Barone CM, McGee ME, Cartwright CC, Baker CL : Endoscopy-assisted wide-vertex craniectomy, barrel stave osteotomies, and postoperative helmet molding therapy in the management of sagittal suture craniosynostosis. J Neurosurg 100(5 Suppl Pediatrics) : 407417, 2004

14. Jones RF, Kwok BC, Stening WA, Vonau M : Neuroendoscopic third ventriculostomy. A practical alternative to extracranial shunts in non-communicating hydrocephalus. Acta Neurochir Suppl 61 : 79-83, 1994

15. Jones RF, Stening WA, Brydon M : Endoscopic third ventriculostomy.
Neurosurgery 26 : 86-91; discussion 91-92, 1990

16. Li KW, Nelson C, Suk I, Jallo GI : Neuroendoscopy: past, present, and future. Neurosurg Focus 19 : E1, 2005

17. Mixter WJ : Ventriculoscopy and puncture of the floor of the third ventricle: preliminary report of a case. Boston Med Surg J 188 : 277-278, 1923

18. Nulsen FE, Spitz EB : Treatment of hydrocephalus by direct shunt from ventricle to jugular vain. Surg Forum 1951 : 399-403

19. Oi $S$, Abbott $R$ : Loculated ventricles and isolated compartments in hydrocephalus: their pathophysiology and the efficacy of neuroendoscopic surgery. Neurosurg Clin N Am 15 : 77-87, 2004

20. Rekate HL, Feiz-Erfan I, Ng YT, Gonzalez LF, Kerrigan JF : Endoscopic surgery for hypothalamic hamartomas causing medically refractory gelastic epilepsy. Childs Nerv Syst 22 : 874-880, 2006

21. Sgouros $S$ : Neuroendoscopy: current status and future trends, ed 1. Heidelberg : Springer Science \& Business Media, 2013

22. Vries JK : An endoscopic technique for third ventriculostomy. Surg Neurol 9 : 165-168, 1978

23. Walker ML : History of ventriculostomy. Neurosurg Clin N Am 12 : 101-110, viii, 2001

24. Wellons JC 3rd, Tubbs RS, Banks JT, Grabb B, Blount JP, Oakes WJ, et al. : Long-term control of hydrocephalus via endoscopic third ventriculostomy in children with tectal plate gliomas. Neurosurgery 51 : 63-67; discussion 67-68, 2002

25. Yamini B, Refai D, Rubin CM, Frim DM : Initial endoscopic management of pineal region tumors and associated hydrocephalus: clinical series and literature review. J Neurosurg 100(5 Suppl Pediatrics) : 437-441, 2004 